\title{
FULFILLMENT OF EXERCISE NEEDS AMONG PREGNANT WOMEN DURING THE COVID-19 PANDEMIC
}

\author{
R. Khairiyatul Afiyah ${ }^{1}$, Nurul Kamariyah ${ }^{2}$, Lono Wijayanti ${ }^{3}$, Juliatik Ragil Yhusnain ${ }^{4}$ \\ ${ }^{1234}$ Department of Nursing, Faculty of Nursing and Midwifery, Universitas Nahdlatul Ulama Surabaya, \\ 60243 Surabaya, East Java, Indonesia
}

\section{Article history: \\ Received: July 30, 2021 \\ Accepted: September 10, 2021 \\ Correspondence: \\ Juliatik Ragil Yhusnain \\ Department of Nursing, Faculty \\ of Nursing and Midwifery, \\ Universitas Nahdlatul Ulama \\ Surabaya, 60243 Surabaya, \\ East Java, Indonesia \\ Email: \\ juliatikragil538@gmail.com \\ Keywords: Covid19; fulfillment of exercise needs; pregnancy; pregnant women \\ DOI: \\ $10.33086 /$ nhc.v 1 i 2.2276}

\begin{abstract}
Background: During the Covid-19 pandemic, many restrictions on almost all routine services including maternal and newborn health services. Some pregnant women are reluctant to go to health facilities for fear of contracting it. The exercise need fulfillment of pregnant women's is disrupted by a pandemic because the gym and the park are closed or fear of the virus exposure when exercising outside the home.

Objective: The purpose of the study was to describe the exercise need fulfillment of pregnant women during the Covid-19 pandemic at Jagir Health Center Surabaya.

Methods: This study used descriptive design. The sample was 40 pregnant women in the 2nd and 3rd trimester at Jagir Health Center Surabaya which obtained bytotal sampling technique. The research variable was the exercise need fulfillment of pregnant women during the Covid-19 pandemic. The research instruments was questionnaires and then data were analyzed using frequency distribution tables.

Results: The study results found that out of 40 respondents, almost entirely pregnant women $(82.5 \%)$ had poor exercise need fulfillment and $17.5 \%$ pregnant women had good exercise need fulfillment during the Covid-19 pandemic.

Conclusion: The exercise need fulfillment of pregnant women during the Covid19 pandemic was poor. The role of nurses can improve and maintain regular exercise in pregnant women. In education, it is important to emphasize that moderate amounts of exercise 150 minutes/week such as walking and yoga can be done in various ways, such as exercising indoors or viewing videos from YouTube, zooming during the Covid-19 pandemic to increase immunity.
\end{abstract}

\section{INTRODUCTION}

The world has been proclaiming war against the coronavirus since its first appearance in Wuhan of China's Hubei Province in late 2019. Covid-19 has become an outbreak and hit various countries in the world without exception in Indonesia. More than thousands of people have died to date. The World Health Organization (WHO) declared Covid-19 as a pandemic (Sohrabi, Alsafi, Neill, Khan, \& Kerwan, 
2020). The Covid-19 pandemic has caused a negative impact on physical and mental health around the world. Pregnant women are at a higher risk of depression compared to the general public which might be exacerbated by pandemics. Moderate exercise can help support mental health during pregnancy. Exercise routines in pregnant women are plagued by pandemics, especially in metropolitan areas (for example, because gyms and parks are closed or fear of exposure to viruses while exercising outside densely populated areas). Conversely, women in less densely populated areas may feel safe going out to do sports. (Gildner, Laugier, \& Thayer, 2021).

During the Covid-19 pandemic, many restrictions were implemented on almost all routine services including in maternal and newborn health services. As pregnant women are reluctant to go to health centers or other health facilities for fear of contracting it, the advice delays pregnancy examinations and classes for pregnant women. The antenatal service guidelines were divided by zone area, service programs for pregnant women such as pregnant women classes for green zones (not affected / no cases of Covid-19) can be carried out by face-to-face methods with a maximum of 10 participants and must follow strict health protocols, and for areas with yellow zones (low risk), orange (moderate risk), red (high risk) has delayed implementation during the Covid-19 pandemic or implemented through online communication media (Video Call, YouTube, and Zoom) (Kemenkes RI, 2020).

Data from the National Population and Family Planning Agency of East Java (2020), from February to July 2020, the pregnancy rate rise and fell by no more than $1 \%$. From February to March 2020 , the pregnancy rate inclined by $0.09 \%$ from 229,667 pregnancies to 232,287 pregnancies. In contrast, the number actually dropped by 0.03 in the following month to reach 227,260 pregnancies. But overall, the data tend to increase (BKKBN, 2020).

A 2015 survey by the University of Campinas and the University of Ceara - Brazil found that 1,279 women, $55.2 \%$ stopped exercising due to pregnancy, $29.3 \%$ continued to exercise, and $15.5 \%$ continued to exercise but by decreasing their intensity and frequency. The prevalence was lower in the first trimester $13.6 \%$, the third trimester $13.4 \%$, and higher in the second trimester $17.8 \%$. The proportion of pregnant women who exercised at least 150 minutes per week was lower: $7.2 \%, 7.6 \%$, and $4.7 \%$ in the first, second, and third trimesters. Of the 981 women who didn't exercise much before pregnancy, 117 (11.9\%) started exercising during pregnancy. The most common first exercise performed in the first trimester was walking (82.2\%), the second most common exercise was an aerobic water in the second and third trimesters (Nascimento, Surita, Godoy, Kasawara, \& Morais, 2015). A 2020 survey of 445 pregnant women and postpartum women showed that $50 \%$ less exercise during lockdown than ever before was affected unconstitutionally by lockdown measures (Atkinson et al., 2020). A preliminary analysis conducted by the Department of Anthropology and Ecology in 2020 found that from the sample showed 
that a high percentage of respondents (47.2\%) expressly reported less exercise after the pandemic, while fewer respondents reported that they exercised more (9.15\%) (Gildner et al., 2021).

Exercise can facilitate the labor process and reduce the risk of aches during the second and third trimesters of pregnancy. This is evidenced by research conducted by Katrine Mari Owe (2012) in Norway whichrevealed that exercising in mid-pregnancy can reduce the prevalence of low back pain. (Gjestland, Bø, Owe, \& Eberhard-Gran, 2013). The physical exercise need for pregnant women is very good because it can improve mood, make the body fit and healthy. Exercise improved the lungs ability to inhale plenty oxygen to be carried by the blood throughout the body, including to the smallest blood vessels. This makes combustion (metabolism) optimal, including the immune system. Therefore, the more regular pregnant women do exercise, will minimize the possibility of illness, the mother will be healthier, and this greatly affects the nutritional supply to the fetus in the womb (Chomaria, 2012). The American College of Obstetricians and Gynecologists publishes guidelines for exercise during pregnancy and advises that any woman without pregnancy complications can exercise moderately for at least 30 minutes a day.

During the ongoing pandemic, fear and anxiety of being infected with Covid-19 or transmitting the infection to other family members resulted in increased stress on pregnant women. Pregnant women are strongly encouraged to keep exercising even in the situation of the Covid-19 pandemic, there are several sports that pregnant women can do such as yoga, walking, swimming and water sports, static cycling, pregnant gymnastics, and pelvic floor exercises. (Hayman, Mel\&Brown, 2016).

\section{METHODS}

\section{Study Design}

The research design used was a descriptive method.

\section{Settings}

This research was conducted at the Jagir Health Center Surabaya from March to June 2021.

\section{Research subject}

The population of this study was pregnant women with trimesters 2 and 3 who routinely conducted examinations for the last 3 months at Jagir Surabaya Health Center, which numbers 40 which were included in the criteria of inclusion and exclusion. The inclusion criteria for determining the subject of the study were 1) Pregnant women who willing to be respondents, 2) Pregnant women with good health, 3) Pregnant women who able to read and write. The exclusion criteria were pregnant women with chronic diseases. The study subjects of 40 respondents were taken through the total sampling technique. The mother who was the subject of the study, then signed the informed Consent provided by the researcher. 


\section{Instruments}

Data was collected using questionnaires which modified by the researchers and consisting of 3 items of questions. The questions were about the frequency and the type of exercise of pregnant women did. The exercise need fulfillment of pregnant women using the frequency of exercise that is if doing 150 minutes of exercise in 1 week (The American Collage Of Obstetricians And Gynecologist, 2015) With a good category of 150 minutes/week and less good if $\leq 150$ minutes/week.

\section{Data collection}

The research was conducted during the Covid-19 pandemic in Jagir Health Center Surabaya. Researchers coordinated with the Surabaya Jagir Health Center related to the sampling of research. The data taken was the pregnant women in the 2 nd and 3rd trimesters who routinely conducted examinations in the last 3 months in Jagir Health Center Surabaya. After getting the data of respondents, the questionnaire sheets were distributed to pregnant women before they did routine examinations and a brief explanation was delivered before they asked to fill out questionnaires. After the mother agreed to be a respondent, the informed consent were given to the respondent, if the respondent was not willing then the researcher did not force the respondent to approve the approval sheet. The questionnaire sheet was returned to the researcher after completed. When researchers distributed questionnaires to respondents, researchers continued to follow health protocols to prevent Covid-19 transmission. After the questionnaire sheet filled out, the respondents were given a memento as a sign of gratitude for being a respondent.

\section{Data Analysis}

The results of the data analysis were presented in the form of a frequency and percentage distribution table. The data displayed are frequency distribution tables and percentage demographic characteristics, distribution and frequency tables, and percentages of the exercise need fulfilment.

\section{Ethical Consideration}

This research had been approved for ethical test from the Health Research Ethics Commission of Nahdlatul Ulama University Surabaya (No. 117/EC/KEPK/UNUSA/2021).

\section{RESULTS}

Based on table 1 it can be known that $72.5 \%$ of respondents aged $26-35$ years, $67.5 \%$ were middle educated, $47.5 \%$ were housewives, $62.5 \%$ were trimester $3,65 \%$ of the type of exercise done was walking, and $82.5 \%$ of pregnant women had poor fulfillment of exercise needs. 
Table 1. Subject Characteristics

\begin{tabular}{|c|c|c|}
\hline Characteristics & Frequency & Percentage $(\%)$ \\
\hline \multicolumn{3}{|l|}{ Age (year): } \\
\hline $17-25$ & 9 & 22.5 \\
\hline $26-35$ & 29 & 72.5 \\
\hline $36-45$ & 2 & 5.0 \\
\hline Total & 40 & 100 \\
\hline \multicolumn{3}{|l|}{ Education } \\
\hline Basic & 6 & 15.0 \\
\hline Intermediate & 27 & 67.5 \\
\hline College & 7 & 17.5 \\
\hline Total & 40 & 100 \\
\hline \multicolumn{3}{|l|}{ Work } \\
\hline Trader & 11 & 27.5 \\
\hline Labor/Farmer & 2 & 5.0 \\
\hline Civil Servant & 5 & 12.5 \\
\hline Self-employed & 3 & 7.5 \\
\hline Housewife & 19 & 47.5 \\
\hline Total & 40 & 100 \\
\hline \multicolumn{3}{|l|}{ Trimester } \\
\hline 1 & 0 & 0.0 \\
\hline 2 & 15 & 37.5 \\
\hline 3 & 25 & 62.5 \\
\hline Total & 40 & 100 \\
\hline \multicolumn{3}{|l|}{ Exercise Type } \\
\hline Yoga & 7 & 17.5 \\
\hline Walk & 26 & 65.0 \\
\hline Pregnant Gymnastics & 7 & 17.5 \\
\hline Total & 40 & 100 \\
\hline \multicolumn{3}{|l|}{ Fulfillment of exercise Needs } \\
\hline Poor & 33 & 82.5 \\
\hline Good & 7 & 17.5 \\
\hline Total & 40 & 100 \\
\hline
\end{tabular}

Source: Primary Data, June 2021

\section{DISCUSSION}

The Covid-19 pandemic has changed the exercise need fulfillment for pregnant women. During the Covid-19 pandemic, it is feared that pregnant women are vulnerable to contracting while doing exercises and have to reduce mobility outside the home. Because the current pandemic imposes restrictions on outdoor physical activity, expectant mothers have little choice about how to access exercise classes. This study is in line with prior study that conducted by Gildner (2020) showing that a percentage of respondents $(47.2 \%)$ reported exercising less after the start of the pandemic, while fewer respondents reported that they exercised more (9.15\%) (Gildner et al., 2021). 
According to the American Pregnancy Association in 2018 (American Pregnancy Association, 2018), exercise is physical activity that enhances or maintains physical fitness and overall health and fitness. Due to the serious health problems posed by the current global pandemic, the activity restrictions caused by the Covid-19 pandemic impacted on the lifestyle of the pregnant mother population and could be a risk factor for various changes. The challenge is to initiate strategies to increase and maintain overall exercise in pregnant women. In health promotion it is important to emphasize that moderate exercise can be achieved in many ways, and it is important to choose enjoyable exercise.

The age range of 20-35 years is a good age for pregnant women. At that age the reproductive organs have developed and functioned optimally, as well as psychological factors. This will reduce various risk factors during pregnancy such as miscarriage, bleeding, and even death. Likewise, when carrying out the delivery process the risk will also be smaller.

Based on table 1, total of $67.5 \%$ respondents have secondary education. In essence, education is a human effort to improve knowledge, which is obtained from formal and non-formal institutions. The education level can affect the pregnant women interest in exercising because of their knowledge, which knowledge is the result after people have sensed a certain object. In this case, the object in question is interest which is influenced by knowledge in the form of impact when doing sports during pregnancy. This interest is influenced by education through one's knowledge/one's mindset in doing something. This mindset raises a person's interest in doing pregnancy exercises

Based on table $147.5 \%$ of pregnant women work as housewives, and 19 respondents work as housewives, as many as 11 respondents wee in the third trimester. When entering the third trimester, women who are pregnant experience many physical and psychological changes. The pregnant women usually feel the psychic condition in the form of anxiety facing labor. There are also those who feel depressed to depression. While changes in the physical usually occur the stomach is getting bigger. Physical changes cause the mother to be passive to exercise and fatigue.

Based on table 1, of 40 respondents, 25 respondents $(62.5 \%)$ were in the third trimester and of 33 respondents with poor compliance, 20 respondents $(60.6 \%)$ were in the third trimester. Pregnant women who rarely exercise in the third trimester experience higher weight gain. The bigger the stomach makes pregnant women often tired and make pregnant women passive to do physical activity, especially exercising. Research conducted by Obstetrics \& Gynecology in 2010 found that of 417 pregnant women as much as $117(28.1 \%)$ were exercise irregularly in the third trimester of pregnancy on the grounds of pregnancy complaints, as many as $47(11.3 \%)$ did not do regular exercise in the third trimester of pregnancy on the grounds of not having enough time. (Haakstad, Voldner, Henriksen, \& B $\varnothing, 2009$ ).

Based on table 1 (65\%), it can be concluded that walking is beneficial for pregnant women in the third trimester because it can strengthen the leg and pelvic muscles so that they can be stronger when 
giving birth. Doing walking exercise is useful in reducing swelling in the lower legs and positioning the fetal head to move downwards (making it easier for normal delivery). By doing walking exercise in the morning, it will discipline mothers to get up early, exercise regularly in the morning, not to be lazy. So that during the day the mother does not get tired quickly. The more often the mother exercises in the morning, which is 150 minutes/week, the more health the mother's condition will be.

Research conducted by the Shanghai University of Sport in 2019 showed that walking exercise for pregnant women was beneficial for both mother and fetus. For mothers, there was a strong evidence that walking during pregnancy, especially at a brisk pace, could reduce the risk of several complications including gestational diabetes (GDM) (20\%), reduced risk of preeclampsia (33\%), and reduced risk of excessive weight gain (29\% - 44\%). For the fetus, it showed that walking during pregnancy lower the risk of macrosomia (14\% - 39\%), and could reduce the risk of preterm birth (36\% - 64\%). (Connolly et al., 2019).

\section{LIMITATION}

The limited sample in this study caused by the pandemic and collect the data used strict health protocol.

\section{CONCLUSION}

The main findings in this study is almost all pregnant women at the Jagir Health Center in Surabaya had poor exercise need fulfilment during the Covid-19 pandemic. The nurses should increase and maintain regular exercise for pregnant women. In education, it is important to emphasize that moderate exercise of 150 minutes/week such as walking and yoga can be done in various ways such as exercising at home or watching videos from YouTube, zooming during the Covid-19 pandemic to increase body immunity. Further, this study result are expected to be used as a basis or references to fulfilling the exercise need of pregnant women during the Covid-19 pandemic in the Surabaya and surrounding areas.

\section{AUTHOR CONTRIBUTION}

R. Khairiyatul Afiyah : Drafting manuscripts, analyzing data, contributing to interpretation of results.

Nurul Kamariyah $\quad$ : Develop instruments, and compose scripts.

Lono Wijayanti : Drafting the manuscript, and contributing to the interpretation of the results.

Juliatik Ragil Yhusnain : Collecting literature, compiling manuscripts, collecting data and conducting data analysis. 


\section{ORCHID}
R. Khairiyatul Afiyah : http://orcid.org/0000-0002-9416-264
Nurul Kamariyah $\quad$ : http://orcid.org/0000-0002-4548-8172
Juliatik Ragil Yhusnain : https://orcid.org/0000-0002-6229-7108

\section{CONFLICT OF INTEREST}

The authors had no conflict of interest.

\section{ACKNOWLEDGEMENT}

The author would like to thank all respondents and to all parties who have helped in completing this research until the preparation of this manuscript, Parents and family who always pray for, support, provide direction, and provide both moral and material assistance, and Jagir Health Center Surabaya, who has given me permission to conduct this research.

\section{REFERENCE}

American Pregnancy Association. (2018). Exercise During Pregnancy.

Atkinson, L., De Vivo, M., Hayes, L., Hesketh, K. R., Mills, H., Newham, J. J., ... Smith, D. M. (2020). Encouraging physical activity during and after pregnancy in the COVID-19 era, and beyond. International Journal of Environmental Research and Public Health, 17(19), 1-9. https://doi.org/10.3390/ijerph17197304

BKKBN. (2020). Keluarga Berencana.

Chomaria, N. (2012). Olahraga Bagi Ibu Hamil dan Menyusui. Jakarta: PT Elex Media Komputindo.

Connolly, C. P., Conger, S. A., Montoye, A. H. K., Marshall, M. R., Schlaff, R. A., Badon, S. E., \& Pivarnik, J. M. (2019). Walking for health during pregnancy: A literature review and considerations for future research. Journal of Sport and Health Science, 8(5), 401-411. https://doi.org/10.1016/j.jshs.2018.11.004

Gildner, T. E., Laugier, E. J., \& Thayer, Z. M. (2021). Exercise routine change is associated with prenatal depression scores during the COVID-19 pandemic among pregnant women across the United States. PLoS ONE, 15(12 December), 1-15. https://doi.org/10.1371/journal.pone.0243188

Gjestland, K., Bø, K., Owe, K. M., \& Eberhard-Gran, M. (2013). Do pregnant women follow exercise guidelines? Prevalence data among 3482 women, and prediction of low-back pain, pelvic girdle pain and depression. British Journal of Sports Medicine, 47(8), 515-520. https://doi.org/10.1136/bjsports-2012-091344 
Haakstad, L. A. H., Voldner, N., Henriksen, T., \& Bø, K. (2009). Why do pregnant women stop exercising in the third trimester? Acta Obstetricia et Gynecologica Scandinavica, 88(11), 12671275. https://doi.org/10.3109/00016340903284901

Hayman, Mel\&Brown, W. J. (2016). Exercise in Pregnancy And The Postpartum Period position Statement. Sport Medicine Australia.

Kemenkes RI. (2020). Pedoman pelayanan antenatal, persalinan, nifas, dan bayi baru lahir di Era Adaptasi Baru.

Nascimento, S. L., Surita, F. G., Godoy, A. C., Kasawara, K. T., \& Morais, S. S. (2015). Physical activity patterns and factors related to exercise during pregnancy: A cross sectional study. PLoS ONE, 10(6). https://doi.org/10.1371/journal.pone.0128953

Sohrabi, C., Alsafi, Z., Neill, N. O., Khan, M., \& Kerwan, A. (2020). Since January 2020 Elsevier has created a COVID-19 resource centre with free information in English and Mandarin on the novel coronavirus COVID- 19. The COVID-19 resource centre is hosted on Elsevier Connect, the company' s public news and information. (January).

The American Collage Of Obstetricians And Gynecologist. (2015). Physical Activity And Exercise During Pregnancy And The Postpartum Period. Retrieved from The American Collage Of Obstetricians And Gynecologist website: https://www.acog.org/clinical/clinicalguidance/committee-opinion/articles/2020/04/physical-activity-and-exercise-during-pregnancyand-the-postpartum-period 